\title{
Secretin Regulates Excitatory GABAergic Neurotransmission to GnRH Neurons via Retrograde NO Signaling Pathway in Mice
}

\author{
Veronika Csillag',2, Csaba Vastagh ${ }^{1}$, Zsolt Liposits ${ }^{1,3+}$ and Imre Farkas ${ }^{4 \star t}$ \\ ${ }^{1}$ Laboratory of Endocrine Neurobiology, Institute of Experimental Medicine, Hungarian Academy of Sciences, Budapest, \\ Hungary, ${ }^{2}$ Roska Tamás Doctoral School of Sciences and Technology, Faculty of Information Technology and Bionics, \\ Pázmány Péter Catholic University, Budapest, Hungary, ${ }^{3}$ Department of Neuroscience, Faculty of Information Technology \\ and Bionics, Pázmány Péter Catholic University, Budapest, Hungary, ${ }^{4}$ Laboratory of Reproductive Neurobiology, Institute \\ of Experimental Medicine, Hungarian Academy of Sciences, Budapest, Hungary
}

OPEN ACCESS

Edited by:

Emilio Carbone,

University of Turin, Italy

Reviewed by:

Andrea Marcantoni,

University of Turin, Italy

John J. Hablitz,

The University of Alabama at Birmingham, United States

${ }^{*}$ Correspondence: Imre Farkas

farkas.imre@koki.mta.hu; farkas@koki.hu

+Senior co-authors

Specialty section:

This article was submitted to

Cellular Neurophysiology,

a section of the journal

Frontiers in Cellular Neuroscience

Received: 22 May 2019

Accepted: 30 July 2019

Published: 23 August 2019

Citation:

Csillag V, Vastagh C, Liposits Z

and Farkas I (2019) Secretin

Regulates Excitatory GABAergic Neurotransmission to GnRH Neurons via Retrograde NO Signaling Pathway in Mice. Front. Cell. Neurosci. 13:371. doi: 10.3389/fncel.2019.00371
In mammals, reproduction is regulated by a wide range of metabolic hormones that maintain the proper energy balance. In addition to regulating feeding and energy expenditure, these metabolic messengers also modulate the functional performance of the hypothalamic-pituitary-gonadal (HPG) axis. Secretin, a member of the secretinglucagon-vasoactive intestinal peptide hormone family, has been shown to alter reproduction centrally, although the underlying mechanisms have not been explored yet. In order to elucidate its central action in the neuroendocrine regulation of reproduction, in vitro electrophysiological slice experiments were carried out on $\mathrm{GnRH}$ GFP neurons in male mice. Bath application of secretin (100 nM) significantly increased the frequency of the spontaneous postsynaptic currents (sPSCs) to $118.0 \pm 2.64 \%$ compared to the control, and that of the GABAergic miniature postsynaptic currents (mPSCs) to $147.6 \pm 19.19 \%$. Resting membrane potential became depolarized by $12.74 \pm 4.539 \mathrm{mV}$ after secretin treatment. Frequency of evoked action potentials (APs) also increased to $144.3 \pm 10.8 \%$. The secretin-triggered elevation of the frequency of mPSCs was prevented by using either a secretin receptor antagonist $(3 \mu \mathrm{M})$ or intracellularly applied G-protein-coupled receptor blocker (GDP- $\beta$-S; 2 mM) supporting the involvement of secretin receptor in the process. Regarding the actions downstream to secretin receptor, intracellular blockade of protein kinase A (PKA) with KT-5720 $(2 \mu \mathrm{M})$ or intracellular inhibition of the neuronal nitric oxide synthase (nNOS) by NPLA $(1 \mu \mathrm{M})$ abolished the stimulatory effect of secretin on mPSCs. These data suggest that secretin acts on $\mathrm{GnRH}$ neurons via secretin receptors whose activation triggers the cAMP/PKA/nNOS signaling pathway resulting in nitric oxide release and in the presynaptic terminals this retrograde NO machinery regulates the GABAergic input to $\mathrm{GnRH}$ neurons.

Keywords: GnRH neuron, secretin, GABA, retrograde signaling, nitric oxide, reproduction, metabolism 


\section{INTRODUCTION}

Metabolic hormones report information about the actual energy state of the body to the central nervous system (CNS). Many of these hormones produced by the adipose tissue, different enteroendocrine cell populations of the gastrointestinal (GI) tract, and diverse endocrine glands, reach the hypothalamus (Berthoud, 2008), where they powerfully regulate food intake, energy expenditure, stress, water balance, and reproduction (Yamashita et al., 1989; Barash et al., 1996; Ulrich-Lai et al., 2015; Matafome et al., 2017; Hill and Elias, 2018).

In the process of reproduction, hypophysiotropic $\mathrm{GnRH}$ neurons located in the medial preoptic area (mPOA) of the rodent brain, are the key central regulators (Cattanach et al., 1977; Herbison, 2016). Certain metabolic hormones have already been shown to exert direct modulatory effects on GnRH neurons (Roa, 2013). Adiponectin inhibits the GnRH secretion of GT17 cells (Wen et al., 2008) and that of GnRH neurons of female mice (Klenke et al., 2014). Cholecystokinin (CCK) inhibits GnRH neurons directly in adult mice (Giacobini and Wray, 2007) and ghrelin, the orexigenic hormone of the stomach also decreases the firing of $\mathrm{GnRH}$ neurons (Farkas et al., 2013). In contrast, the anorexigenic glucagon-like peptide 1 (GLP-1) increases the activity of GnRH neurons (Farkas et al., 2016).

Secretin is an anorexigenic hormone (Thiriet, 2019), similarly to the GLP-1, and it can serve as a signal molecule reporting level of the energy homeostasis. It was the first hormone discovered in 1902 and released from the S-cells in the intestines (Bayliss and Starling, 1902). Secretin is secreted in the intestine when pylorus of the stomach opens to transfer food into the intestine. It is produced in response to the acid milieu to stimulate bicarbonate secretion from the pancreas to neutralize gastric chyme acidity. In the periphery, secretin serves, therefore, as a local signal to pancreas for neutralizing the acidity of the stomach by secretion of bicarbonates (Bayliss and Starling, 1902). In addition, those features mean that secretin can indeed be considered as a signal molecule of the high energy status of the body. Furthermore, it can cross the intact blood-brain barrier (BBB) (Banks et al., 2002; Dogrukol-Ak et al., 2004) and serve as a peripheral signal to neurons in numerous brain regions.

Secretin is also synthesized in several brain areas. The most intensive secretin immunoreactivity was detected in the Purkinje cells of the cerebellum and in some of the neurons of the deep cerebellar nuclei. Secretin immunoreactivity was also observed in a subpopulation of neurons in the primary sensory ganglia (Koves et al., 2002). Within the hypothalamus, secretin synthesis was described in the magnocellular cells of supraoptic nucleus (SON) and in the magnocellular cells of the paraventricular nucleus (PVN) (Chu et al., 2006).

The G-protein-coupled secretin receptor has a similar structure and belongs to the same receptor subfamily as the vasoactive intestinal peptide (VIP) (Ulrich et al., 1998). Specific binding of secretin to its receptor was found in various brain areas such as the cerebellum, cortex, thalamus, hippocampus, and hypothalamus (Fremeau et al., 1983). Secretin receptor mRNA showed wide distribution in the CNS. It was detected in numerous brain regions for example in the area postrema, cerebellum, central amygdala, hippocampus, thalamus, in the cortex, and in the nucleus tractus solitarii (NTS) (Nozaki et al., 2002). Dense labeling of secretin receptor was observed in the NTS and in the laterodorsal nucleus of the thalamus. Expression of secretin receptor was also found in the hypothalamus (Toth et al., 2013).

Intracerebroventricular injection of secretin increased the expression of $\mathrm{c}$-Fos in several brain regions including the area postrema, medial region of the NTS, paraventricular nucleus, and various cortical areas indicating a central action of the hormone in rats. In other areas secretin attenuated c-Fos immunoreactivity (Welch et al., 2003). In the hypothalamus, intracerebroventricular administration of secretin stimulated vasopressin expression and release, indicating that it had a role in regulating the water homeostasis by modulating the hypothalamo-neurohypophysial axis (Chu et al., 2009).

Electrophysiological effect of secretin was examined first in the rat cerebellar cortex, where secretin facilitated the evoked, spontaneous, and miniature GABAergic inhibitory postsynaptic currents (IPSCs) recorded in Purkinje cells. Secretin mRNA was found in the Purkinje cells, and secretin receptor was present in both Purkinje cells and GABAergic interneurons, suggesting an autocrine regulation (Yung et al., 2001). In other electrophysiological experiments secretin depolarized neurons of the NTS via non-selective cation channels (Yang et al., 2004), while in the PVN it modulated the firing rate of the neurons in vivo (Chen et al., 2013).

Secretin can be regarded as another putative regulator of the reproductive axis, although limited information has been available about the exact role of secretin in the regulation of reproduction so far (Wang et al., 2018). In an early study, intracerebral (IC) injection of secretin into the preoptic region of rats resulted in 10-fold elevation of luteinizing hormone (LH) concentration in the plasma (Kimura et al., 1987). In addition, our earlier works revealed that $\mathrm{GnRH}$ neurons residing in the preoptic area senses the energy status of the body via various homeostatic signaling molecules such as ghrelin and GLP-1 (Farkas et al., 2013, 2016). Therefore, it is highly conceivable that secretin, as one of the signal molecules of the homeostasis, also modulates function of $\mathrm{GnRH}$ neurons. In addition, the anorexigenic hormone GLP-1 increased activity of GnRH neurons (Farkas et al., 2016), thus we hypothesized that secretin also stimulates $\mathrm{GnRH}$ neurons, promoting the reproductive process. However, the exact cellular mechanism of the effect of secretin in the modulation of HPG axis has not been revealed yet. In the present study, therefore, we carried out whole cell patch clamp recordings on GnRH-GFP neurons of male mice to elucidate the effect of secretin on PSCs, and to uncover the second messenger cascade events occurring downstream to the secretin receptor in these neurons.

\section{MATERIALS AND METHODS}

\section{Animals}

Adult male mice were used from local colonies bred at the Medical Gene Technology Unit of the Institute of 
Experimental Medicine Hungarian Academy of Sciences (IEM). They were housed in light (12:12 light-dark cycle, lights on at 06:00 h) - and a temperature-controlled environment $\left(22 \pm 2^{\circ} \mathrm{C}\right.$ ), with free access to standard food and water. $\mathrm{GnRH}$-green fluorescent protein (GnRH-GFP) transgenic mice $(n=57)$ bred on a $\mathrm{C} 57 \mathrm{Bl} / 6 \mathrm{~J}$ genetic background were used for electrophysiological experiments. In this animal model, a GnRH promoter segment drives selective GFP expression in the GnRH neurons (Suter et al., 2000).

\section{Ethics Statement}

All animal studies were carried out with permissions from the Animal Welfare Committee of the IEM Hungarian Academy of Sciences (Permission Number: A5769-01) and in accordance with legal requirements of the European Community (Directive 2010/63/EU). All animal experiments described below are designed in accord with accepted standards of animal care and all efforts were made to minimize animal suffering. We carried out sacrifice of animals by decapitation in deep anesthesia by Isoflurane inhalation.

\section{Brain Slice Preparation}

Brain slice preparation was carried out as described earlier (Farkas et al., 2010). Briefly, after decapitation the heads were immersed in ice-cold $\mathrm{Na}$-free cutting solution, continuously bubbled with carbogen, a mixture of $95 \% \mathrm{O}_{2}$ and $5 \% \mathrm{CO}_{2}$, and the brains were removed rapidly from the skull. The cutting solution contained the following (in $\mathrm{mM}$ ): saccharose $205, \mathrm{KCl}$ 2.5, $\mathrm{NaHCO}_{3} 26, \mathrm{MgCl}_{2}$ 5, $\mathrm{NaH}_{2} \mathrm{PO}_{4}$ 1.25, $\mathrm{CaCl}_{2}$ 1, glucose 10 . Hypothalamic blocks were dissected, and $250 \mu \mathrm{m}$-thick coronal slices were prepared from the medial POA with a VT-1000S vibratome (Leica Microsystems, Wetzlar, Germany) in the icecold Na-free oxygenated cutting solution. The slices containing POA were transferred into artificial cerebrospinal fluid (aCSF) (in mM): $\mathrm{NaCl} 130, \mathrm{KCl} 3.5, \mathrm{NaHCO}_{3} 26, \mathrm{MgSO}_{4} 1.2, \mathrm{NaH}_{2} \mathrm{PO}_{4}$ $1.25, \mathrm{CaCl}_{2} 2.5$, glucose 10 bubbled with carbogen and left in it for $1 \mathrm{~h}$ to equilibrate. Equilibration started at $33^{\circ} \mathrm{C}$ and it was let to cool down to room temperature.

Recordings were carried out in carbogenated aCSF at $33^{\circ} \mathrm{C}$. Axopatch-200B patch-clamp amplifier, Digidata-1322A data acquisition system, and pCLAMP 10.4 software (Molecular Devices Co., Silicon Valley, CA, United States) were used for recording. Neurons were visualized with a BX51WI IR-DIC microscope (Olympus Co., Tokyo, Japan). The patch electrodes (OD $=1.5 \mathrm{~mm}$, thin wall; WPI, Worcester, MA, United States) were pulled with a Flaming-Brown P-97 puller (Sutter Instrument Co., Novato, CA, United States).

GnRH-GFP neurons in the close proximity of the vascular organ of lamina terminalis (OVLT; Bregma 0.49-0.85 mm) were identified by brief illumination at $470 \mathrm{~nm}$ using an epifluorescent filter set, based on their green fluorescence, typical fusiform shape and characteristic topography (Suter et al., 2000).

Whole-cell patch-clamp measurements started with a control recording $(5 \mathrm{~min})$, then secretin was pipetted into the aCSFfilled measurement chamber containing the brain slice in a single bolus and the recording continued for a further $10 \mathrm{~min}$. Pretreatment with secretin antagonist $(1 \mu \mathrm{M})$ started $10 \mathrm{~min}$ before adding the secretin and the antagonist was continuously present in the aCSF during the electrophysiological recording. Intracellularly applied drugs, such as the membrane impermeable G-protein inhibitor GDP- $\beta$-S (2 mM, Sigma; St. Louis, MO, United States), NO synthase inhibitor NPLA (1 $\mu \mathrm{M}$; Tocris; Bristol, United Kingdom), and PKA blocker KT-5720 (2 $\mu \mathrm{M}$; Tocris) were added to the intracellular pipette solution and after achieving whole-cell patch clamp configuration, we waited $15 \mathrm{~min}$ to reach equilibrium in the intracellular milieu before starting recording. Each neuron served as its own control when drug effects were evaluated.

\section{Reagents and Chemicals \\ Extracellularly Used Drugs}

Secretin (30 nM-1 $\mu \mathrm{M}$; rat, Tocris); Secretin antagonist [3 $\mu \mathrm{M}$; Secretin 5-27; TFTSELSRLQDSARLQRLLQGLV (Williams et al., 2012)], $\mathrm{GABA}_{\mathrm{A}}-\mathrm{R}$ blocker picrotoxin [100 $\mu \mathrm{M}$, Sigma; (Seidl et al., 2014; Keshavarzi et al., 2015)].

\section{Intracellularly Used Drugs}

Neuronal nitric oxide synthase (nNOS) inhibitor N-propylL-arginine hydrochloride [NPLA; $1 \mu \mathrm{M}$; Tocris (Chow et al., 2012; Filpa et al., 2015; Gong et al., 2015)]; G-protein inhibitor, Guanosine $5^{\prime}$-[ $\beta$;-thio] diphosphate [GDP- $\beta$-S; $2 \mathrm{mM}$; Sigma, (Meis et al., 2002; Ponzio and Hatton, 2005; McDermott and Schrader, 2011)]; protein kinase-A (PKA) inhibitor (9S,10S,12R)-2,3,9,10,11,12-Hexahydro-10-hydroxy-9-methyl1-oxo-9,12-epoxy-1H-diindolo[1,2,3-fg: $3^{\prime}, 2^{\prime}, 1^{\prime}$-kl] pyrrolo[3,4i] $[1,6]$ benzodiazocine-10-carboxylic acid hexyl ester [KT-5720; $2 \mu \mathrm{M}$; Tocris (Glovaci et al., 2014; Kaneko et al., 2016)].

\section{Whole Cell Patch Clamp Experiments}

The spontaneous postsynaptic currents (sPSCs) and miniature postsynaptic currents (mPSCs) in GnRH neurons were measured as described earlier (Farkas et al., 2010). Briefly, the neurons were voltage-clamped at $-70 \mathrm{mV}$ holding potential. Intracellular pipette solution contained (in mM): HEPES 10, $\mathrm{KCl} 140$, EGTA 5, $\mathrm{CaCl}_{2}$ 0.1, Mg-ATP 4, Na-GTP 0.4 (pH = 7.3 with $\left.\mathrm{NaOH}\right)$. The resistance of the patch electrodes was 2-3 M 2 . Spike-mediated transmitter release was blocked in all mPSC experiments by adding the voltage-sensitive $\mathrm{Na}$-channel inhibitor tetrodotoxin (TTX, $660 \mathrm{nM}$, Tocris) to the aCSF $10 \mathrm{~min}$ before mPSCs or $\mathrm{V}_{\text {rest }}$ were recorded. The mPSCs recorded under the conditions used in our experiments were related to $\mathrm{GABA}_{\mathrm{A}}-\mathrm{R}$ activation (Sullivan et al., 2003; Farkas et al., 2010). This GABAergic input was also validated in our measurements by picrotoxin $(100 \mu \mathrm{M}$, Tocris). GABAergic input via $\mathrm{GABA}_{\mathrm{A}}-\mathrm{R}$ is excitatory to $\mathrm{GnRH}$ cells (Moenter and DeFazio, 2005; Yin et al., 2008; Herbison and Moenter, 2011). Time distribution graphs of frequencies were generated by using 1-minute time bins to show time courses of effect of secretin.

Resting membrane potential $\left(\mathrm{V}_{\text {rest }}\right)$ was recorded in currentclamp mode with 0 pA holding current. To show action of secretin on the firing, $R_{i n}$, and $C_{m}$ in $\mathrm{GnRH}$ neurons of male mice, current clamp measurements were recorded. Three 900ms-long current steps were applied $(-25,0$, and $+25 \mathrm{pA})$. Firing was analyzed during the depolarizing step. The $\mathrm{R}_{\text {in }}$ 
was determined from the voltage response to the application of hyperpolarizing current. The time constant was the time required to reach $63 \%$ of the maximum voltage response to hyperpolarizing current (Spergel et al., 1999). The $\mathrm{C}_{\mathrm{m}}$ was then calculated by dividing the time constant by the $\mathrm{R}_{\text {in }}$. After control recording, secretin was pipetted into the measurement chamber and $1,3,5$, and $10 \mathrm{~min}$ later the three current steps were repeated.

\section{Statistical Analysis}

Recordings were stored and analyzed off-line. Event detection was performed using the Clampfit module of the PClamp 10.4 software (Molecular Devices Co., Silicon Valley, CA, United States).

Spontaneous postsynaptic currents and mPSC frequencies were calculated as number of PSCs divided by the length of the corresponding time period (5 or $10 \mathrm{~min}$ ). Mean values of the control and treated part of the recording were calculated from these frequency values. All the experiments were self-controlled in each neuron: percentage changes in the parameters of the PSCs were calculated by dividing the value of the parameter in the treated period with that of the control period.

Evoked AP frequency was calculated by dividing the number of events with the length of the respective time period. Percentage changes resulted from secretin application were calculated by dividing the value to be analyzed before and after secretin administration.

Group data were expressed as mean \pm standard error of mean (SEM). Two-tailed Student's $t$ test were applied for comparison of groups and the differences were considered as significant at $p<0.05$. Cumulative probabilities of interevent-intervals of neurons were analyzed by using Kolmogorov-Smirnov test $(p<0.05)$ to show statistical differences between the intereventintervals of the control and secretin treated periods. The analysis of frequency changes in case of the evoked action potentials (APs) was carried out by One-way ANOVA with repeated measurements followed by Dunnett's test.

\section{RESULTS}

\section{Secretin Increased the Frequency of Spontaneous Postsynaptic Currents and Depolarized the Membrane Potential in GnRH Neurons of Male Mice}

Administration of $30 \mathrm{nM}$ secretin revealed no significant change neither in frequency (Figure 1B) nor in amplitude parameters of sPSCs. Rise and decay $\tau$ of sPSCs also presented no significant change (Tables 1, 2, 5).

Frequency of sPSCs after $100 \mathrm{nM}$ secretin administration resulted in a significant increase up to $118.0 \pm 2.64 \%$ of the control values $(3.244 \pm 0.8151 \mathrm{~Hz}, n=8$, Student's $t$-test, $p=0.0005$ ) (Figures $\mathbf{1 A}, \mathbf{B}$ and Table 1). The increase in frequency of the sPSCs started approximately 2 min after the administration of secretin, as shown by the distribution graph under the recording (Figure 1A). Cumulative probability plots also demonstrated significant difference between the control and the treated interevent-intervals (Kolmogorov-Smirnov test, $p=0.0047)$. In contrast, values of amplitude, rise, and decay $\tau$ of the sPSCs presented no significant change (Figure 1A and Tables 2, 5).

Administration of $1 \mu \mathrm{M}$ secretin also significantly increased the frequency of sPSCs to $124.3 \pm 9.404 \%$ (control value: $1.914 \pm 0.519 \mathrm{~Hz}$, Student's $t$-test, $n=7, p=0.049$ ) (Figure 1B and Table 1). The bar graph shows the percentage changes in the frequency of sPSCs resulted from secretin application, demonstrating the dose dependency of the effect of secretin (Figure 1B). Values of amplitude, rise, and decay $\tau$ of the sPSCs after $1 \mu \mathrm{M}$ secretin administration presented no significant change (Tables 2, 5).

\section{Secretin Increased the Frequency of Evoked Action Potentials in GnRH Neurons of Male Mice}

The number of evoked APs increased significantly after secretin administration (100 nM) when measured in current clamp mode in 1 and $3 \mathrm{~min}$ time points. The frequency increased after $1 \mathrm{~min}$ to $144.3 \pm 10.8 \%(p=0.0005)$ and after 3 min up to $138.2 \pm 11.24 \%$ compared to the control value $[11.56 \pm 1.819 \mathrm{~Hz}(p=0.0023)]$. Firing rate showed no significant changes at other time points (Figures 2A,C and Table 3) ( $n=7$; One-way ANOVA with repeated measurements).

The rheobase, which shows the strength of the current required to activate a single action potential, decreased in 6 neurons out of 7, after application of secretin. Firing in 3 neurons of 7 started at $0 \mathrm{pA}$ current injection, suggesting that secretin could increase the spontaneous activity of these neurons. Other passive membrane parameters, such as input resistance $\left(\mathrm{R}_{\mathrm{in}}\right)$ and membrane capacitance $\left(C_{m}\right)$ also showed no significant change (Figures 2D,E and Table 3). The current step measurements showed, that resting membrane potential $\left(\mathrm{V}_{\text {rest }}\right)$ depolarized significantly at 1 and $3 \mathrm{~min}(11.92 \pm 4.487 \mathrm{mV}, p<0.0451$; $13.82 \pm 4.986 \mathrm{mV}, p<0.0392$, Table 3 ) suggesting that elevation in the firing rate resulted from this change in the $V_{\text {rest }}$.

Earlier studies showed that in $\mathrm{GnRH}$ neurons of adult male mice the mPSCs are exclusively excitatory through $\mathrm{GABA}_{\mathrm{A}}$ receptor (Sullivan et al., 2003; Sullivan and Moenter, 2004; Moenter and DeFazio, 2005; Farkas et al., 2010; Herbison and Moenter, 2011). We eliminated all the mPSCs by application of selective $\mathrm{GABA}_{\mathrm{A}}$ receptor blocker picrotoxin and after secretin administration no new PSCs could be observed (not shown) suggesting that the recorded mPSCs in these experiments were $\mathrm{GABA}_{\mathrm{A}}$ receptor-mediated currents.

We hypothesized that $\mathrm{GABA}_{\mathrm{A}}$ receptor plays an exclusive role in the effect of secretin on the firing of $\mathrm{GnRH}$ neurons. The $\mathrm{GABA}_{\mathrm{A}}-\mathrm{R}$ blocker picrotoxin totally eliminated the effect of secretin on the evoked APs of GnRH neurons, there was no residual change (Figures $\mathbf{2 B}, \mathbf{C}$ ). This fact indicates that effect of secretin on the firing rate correlates with the action of secretin on the GABAergic PSC frequency, and the elevation in the firing rate (i.e., the increased excitability) results from the elevated frequency of the GABAergic PSCs. Other passive membrane parameters, such as $R_{i n}$ and $C_{m}$ also showed no significant change 

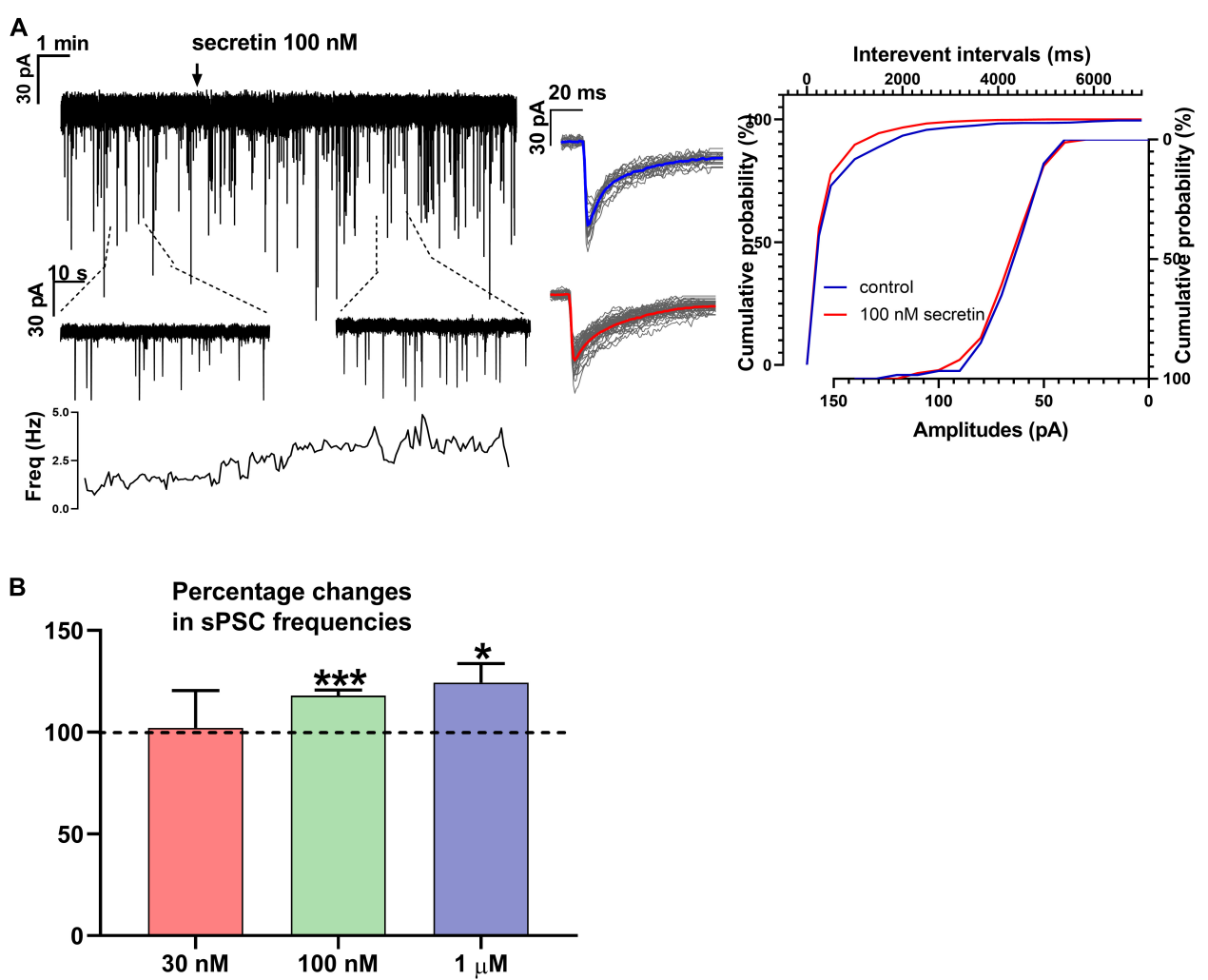

FIGURE 1 | Secretin increases the frequency of sPSC in GnRH neurons. (A) Secretin increased the frequency of the sPSCs with no change in the average amplitude and shape. Average sPSCs next to the recording represent no change in the shape of events after secretin treatment. The inserts below the 15 min recordings are 1-1 min zoomed periods from the recordings before and after secretin administration. The frequency distribution graph under the inserts also reveals that secretin application elevated the sPSC frequency. Cumulative probabilities of the interevent intervals and amplitudes are also presented. (B) The bar graph shows that effect of secretin increasing the sPSC frequency is dose dependent (Student's $t$-test * $p<0.05 ; * * * p<0.001$ ).

TABLE 1 | Changes in the frequency of PSCs after secretin treatment.

\begin{tabular}{|c|c|c|c|c|c|}
\hline & & $\begin{array}{l}\text { Frequency of control } \\
\text { period in } \mathrm{Hz}\end{array}$ & After secretin in $\mathrm{Hz}$ & $\begin{array}{l}\text { Average percentage } \\
\text { changes after secretin }\end{array}$ & $n / N$ \\
\hline \multirow[t]{3}{*}{ sPSC } & $30 \mathrm{nM}$ secretin & $1.348 \pm 0.442$ & $1.232 \pm 0.235$ & $102.10 \pm 4.33$ & $9 / 4$ \\
\hline & $100 \mathrm{nM}$ secretin & $3.244 \pm 0.8155$ & $3.768 \pm 0.958$ & $118 \pm 2.64^{* * *}$ & $8 / 3$ \\
\hline & $1 \mu \mathrm{M}$ secretin & $1.914 \pm 0.509$ & $2.413 \pm 0.6484$ & $124.3 \pm 9.404^{*}$ & $7 / 3$ \\
\hline \multirow[t]{5}{*}{ mPSC } & $100 \mathrm{nM}$ secretin & $1.367 \pm 0.315$ & $1.833 \pm 0.7176$ & $147.6 \pm 19.19^{*}$ & $16 / 7$ \\
\hline & $\begin{array}{l}\text { Secretin receptor } \\
\text { antagonist }+100 \mathrm{nM} \text { secretin }\end{array}$ & $0.7229 \pm 0.2358$ & $0.566 \pm 0.115$ & $92.88 \pm 8.949$ & $8 / 4$ \\
\hline & GDP- $\beta-S$ + 100 nM secretin & $0.632 \pm 0.124$ & $0.6090 \pm 0.1199$ & $102.1 \pm 0.957$ & $10 / 4$ \\
\hline & NPLA + 100 nM secretin & $1.045 \pm 0.2297$ & $1.018 \pm 0.2380$ & $90.38 \pm 4.60$ & $10 / 5$ \\
\hline & KT5720 + 100 nM secretin & $2.016 \pm 0.7367$ & $1.755 \pm 0.5721$ & $97 \pm 5.987$ & $13 / 6$ \\
\hline
\end{tabular}

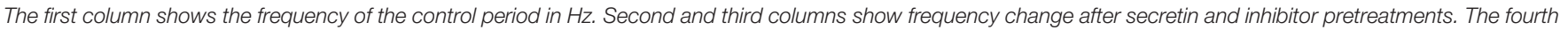
column shows the number of neurons ( $n$ ) and animals $(N)$ used for the experiments (Student's t-test; * $p<0.05$; *** $p<0.001$ ).

(Figures 2D,E and Table 4). The input resistance is the sum of the membrane resistance and the electrode resistance (Barbour, 2014). Supposing that electrode resistance does not change during the measurement, the input resistance is a true measure of the membrane resistance. Therefore, if the input resistance shows no change it indicates that membrane resistance presents no change, too. The current step measurements also showed, that in the presence of picrotoxin $V_{\text {rest }}$ presented no significant change at any time point (Table 4) indicating that GABAergic neurotransmission plays role in the membrane depolarization which eventually results in the elevation in the firing rate.

\section{Secretin Acted Directly on GnRH Neurons via Secretin Receptor}

In order to demonstrate the direct action of secretin on GnRH neurons, mPSCs were recorded in the presence of TTX. The 
TABLE 2 | Changes in the amplitude of PSCs upon secretin treatment.

\begin{tabular}{|c|c|c|c|c|}
\hline & & Amplitude of control period in pA & Average percentage changes after secretin & $n / N$ \\
\hline \multirow[t]{3}{*}{ sPSC } & $30 \mathrm{nM}$ secretin & $31.98 \pm 3.628$ & $96.78 \pm 3.166$ & $9 / 4$ \\
\hline & $100 \mathrm{nM}$ secretin & $54.04 \pm 7.366$ & $97.38 \pm 1.209$ & $8 / 3$ \\
\hline & $1 \mu \mathrm{M}$ secretin & $37.91 \pm 2.727$ & $99.71 \pm 3.160$ & $7 / 3$ \\
\hline \multirow[t]{5}{*}{ mPSC } & $100 \mathrm{nM}$ secretin & $41.77 \pm 3.061$ & $101.3 \pm 2.406$ & $16 / 7$ \\
\hline & Secretin receptor antagonist $+100 \mathrm{nM}$ secretin & $47.75 \pm 3.034$ & $100.3 \pm 2.295$ & $8 / 4$ \\
\hline & GDP- $\beta-S+100$ nM secretin & $76.56 \pm 9.424$ & $101.0 \pm 1.483$ & $10 / 4$ \\
\hline & NPLA + 100 nM secretin & $38.95 \pm 3.347$ & $104.1 \pm 4.037$ & $10 / 5$ \\
\hline & KT5720 + 100 nM secretin & $54.04 \pm 9.231$ & $99.0 \pm 1.665$ & $13 / 6$ \\
\hline
\end{tabular}

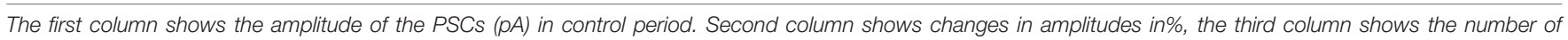
neurons $(n)$ and animals $(N)$ used for the experiments.

A
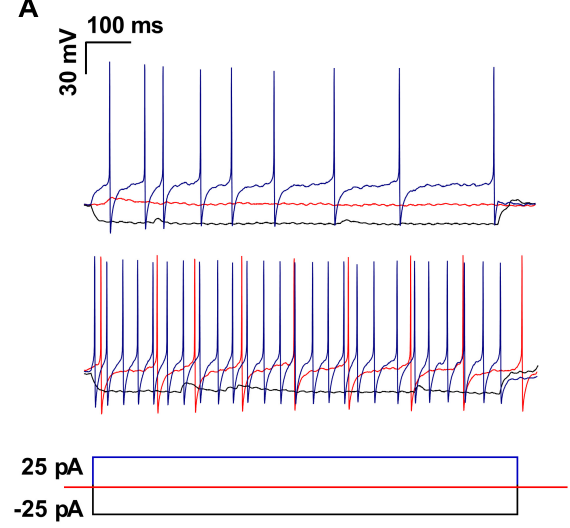

C

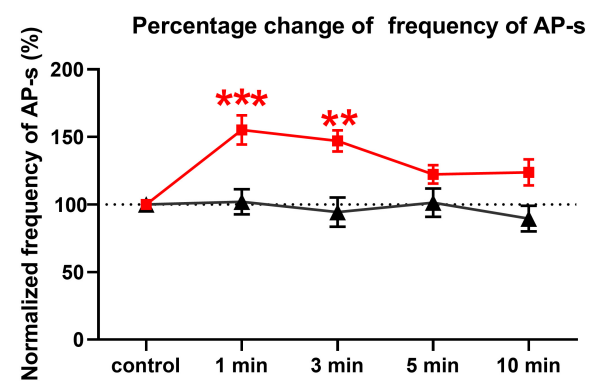

E

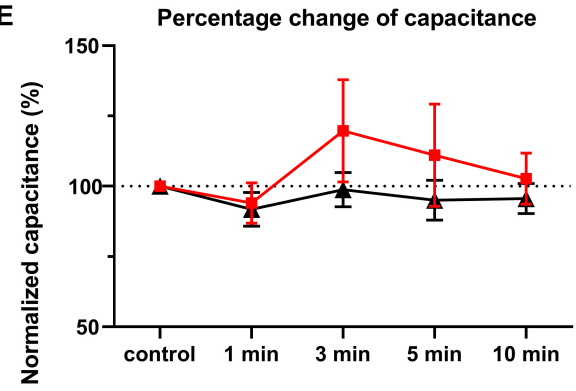

B

control

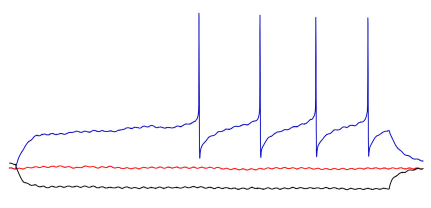

after $3 \mathrm{~min}$
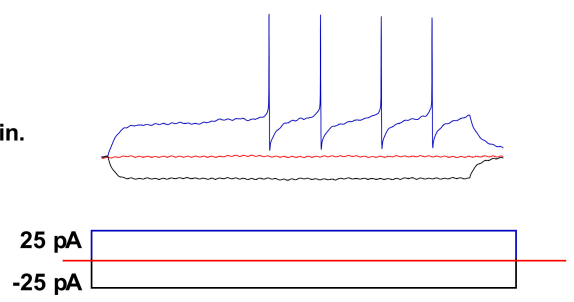

D

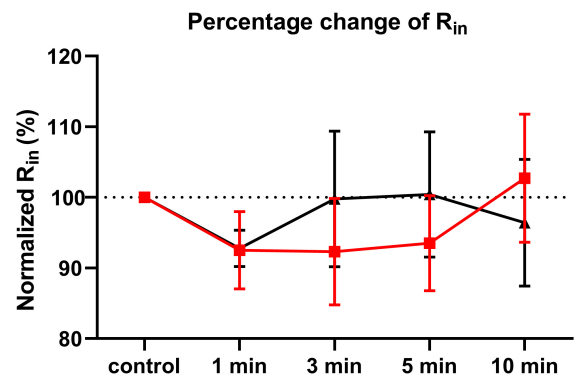

secretin $100 \mathrm{nM}$

picrotoxin+ secretin $100 \mathrm{nM}$

FIGURE 2 | Secretin (100 nM) increases the frequency of the evoked APs. (A) Representative recording shows that frequency of APs evoked by depolarizing current steps elevated 3 min after secretin administration. Also, the rheobase of APs decreased after secretin treatment. There was no change in the average amplitudes of APs. (B) Representative recording of the effect of secretin in the presence of picrotoxin (C) Secretin results in a significant rise in the frequency of APs after 1 and 3 min of its administration (marked by red $\mathbf{\square}$ ) in the presence of picrotoxin there was no significant change (marked by $\mathbf{\Lambda}$ ). (D) Changes in the $\mathrm{R}_{\text {in }}$ represented no significant alteration. (E) Membrane capacitance also showed no significant change. $\left({ }^{* *} p<0.01 ;{ }^{* * *} p<0.001\right)$. 
TABLE 3 | Effect of secretin on the evoked action potentials (APS), the passive membrane properties and $V_{\text {rest }}$.

\begin{tabular}{|c|c|c|c|c|c|c|}
\hline & \multirow[t]{2}{*}{ Control } & \multicolumn{4}{|c|}{ Average percentage or delta changes after secretin } & \multirow[b]{2}{*}{$n / N$} \\
\hline & & $1 \mathrm{~min}$ & $3 \mathrm{~min}$ & $5 \mathrm{~min}$ & $10 \mathrm{~min}$ & \\
\hline Frequency of APs & $11.56 \pm 1.819 \mathrm{~Hz}$ & $144.3 \pm 10.8 \% * * *$ & $138.2 \pm 11.24 \% * *$ & $114.7 \pm 9,45 \%$ & $123.7 \pm 9.76 \%$ & $7 / 3$ \\
\hline Capacitance & $22.66 \pm 3.93 p F$ & $97.57 \pm 6.09 \%$ & $100.6 \pm 7.387 \%$ & $106.4 \pm 6.244 \%$ & $109.6 \pm 7.422 \%$ & $7 / 3$ \\
\hline $\mathbf{R}_{\text {in }}$ & $972 \pm 96.13 M \Omega$ & $92.5 \pm 5.476 \%$ & $92.33 \pm 7.54 \%$ & $93.5 \pm 6.756 \%$ & $102.7 \pm 9.087 \%$ & $7 / 3$ \\
\hline $\mathbf{V}_{\text {rest }}$ & $70.61 \pm 4.498 \mathrm{mV}$ & $11.92 \pm 4.487 \mathrm{mV}^{* *}$ & $13.82 \pm 4.986 \mathrm{mV}^{* *}$ & $10.37 \pm 8.052 \mathrm{mV}$ & $8.540 \pm 6.795 \mathrm{mV}$ & $7 / 3$ \\
\hline
\end{tabular}

TABLE 4 | Effect of secretin on the evoked APs, the passive membrane properties and $V_{\text {rest }}$ in the presence of picrotoxin.

\begin{tabular}{|c|c|c|c|c|c|c|}
\hline & \multirow[t]{2}{*}{ Control } & \multicolumn{4}{|c|}{ Average percentage or delta changes after secretin } & \multirow[b]{2}{*}{$n / \mathrm{N}$} \\
\hline & & $1 \mathrm{~min}$ & $3 \mathrm{~min}$ & $5 \mathrm{~min}$ & $10 \mathrm{~min}$ & \\
\hline Frequency of APs & $15.18 \pm 6.878 \mathrm{~Hz}$ & $102 \pm 9.295 \%$ & $94.40 \pm 10.79 \%$ & $101.4 \pm 10.50 \%$ & $89.60 \pm 9.51 \%$ & $6 / 3$ \\
\hline Capacitance & $18.87 \pm 0.8304 p F$ & $91.80 \pm 6.012 \%$ & $98.80 \pm 6.094 \%$ & $95.0 \pm 7.162 \%$ & $95.60 \pm 5.354 \%$ & $6 / 3$ \\
\hline $\mathbf{R}_{\text {in }}$ & $1048 \pm 116.6 \mathrm{M} \Omega$ & $92.80 \pm 2.296 \%$ & $99.80 \pm 9.604 \%$ & $100.4 \pm 8.875 \%$ & $96.40 \pm 8.976 \%$ & $6 / 3$ \\
\hline $\mathbf{V}_{\text {rest }}$ & $65.14 \pm 5.042 \mathrm{mV}$ & $0.5075 \pm 0.4413 \mathrm{mV}$ & $0.3663 \pm 0.3472 \mathrm{mV}$ & $0.8924 \pm 0.2314 m V$ & $1.5970 \pm 0.7586 \mathrm{mV}$ & $6 / 3$ \\
\hline
\end{tabular}

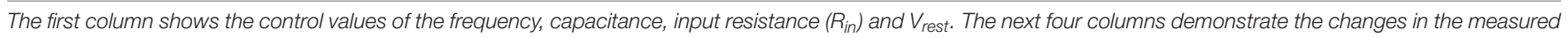

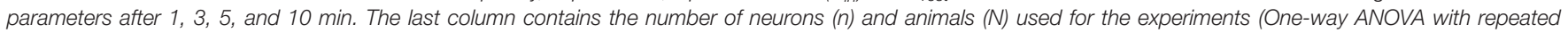
measurements followed by Dunnett's test).

TABLE 5 | Changes in the rise $\tau$ and decay $\tau$ after $100 \mathrm{nM}$ secretin.

\begin{tabular}{|c|c|c|c|c|c|c|}
\hline & & Rise tau (ms) & $\begin{array}{l}\text { Average percentage } \\
\text { changes after secretin }\end{array}$ & Decay tau (ms) & $\begin{array}{l}\text { Average percentage } \\
\text { changes after secretin }\end{array}$ & $n / N$ \\
\hline \multirow[t]{3}{*}{ sPSC } & $30 \mathrm{nM}$ secretin & $3.716 \pm 0.440$ & $103.9 \pm 4.808$ & $22.57 \pm 1.431$ & $102.8 \pm 4.160$ & $9 / 4$ \\
\hline & $100 \mathrm{nM}$ secretin & $4.460 \pm 0.6166$ & $101.6 \pm 7.926$ & $23.05 \pm 1.711$ & $97.88 \pm 3.182$ & $8 / 3$ \\
\hline & $1 \mu \mathrm{M}$ secretin & $4.244 \pm 0.3608$ & $98.38 \pm 5.867$ & $26.17 \pm 1.833$ & $101.9 \pm 1.903$ & $7 / 3$ \\
\hline \multirow[t]{5}{*}{ mPSC } & 100 nM secretin & $4.866 \pm 0.6075$ & $101.7 \pm 12,96$ & $19.07 \pm 2.140$ & $104.6 \pm 12.18$ & $16 / 7$ \\
\hline & $\begin{array}{l}\text { Secretin receptor } \\
\text { antagonist + } 100 \mathrm{nM} \text { secretin }\end{array}$ & $4.081 \pm 0.8153$ & $102.8 \pm 7.947$ & $32.78 \pm 10.22$ & $97.30 \pm 10.82$ & $8 / 4$ \\
\hline & GDP- $\beta-S$ + 100 nM secretin & $3.940 \pm 0.4759$ & $100.03 \pm 10.29$ & $22.96 \pm 4.250$ & $91.20 \pm 7.297$ & $10 / 4$ \\
\hline & NPLA + 100 nM secretin & $3.281 \pm 0.453$ & $106.3 \pm 8.593$ & $21.51 \pm 4.044$ & $102.4 \pm 6.608$ & $10 / 5$ \\
\hline & KT5720 + 100 nM secretin & $4.475 \pm 0.4489$ & $101.8 \pm 10.61$ & $20.26 \pm 1.258$ & $112.5 \pm 10.02$ & $13 / 6$ \\
\hline
\end{tabular}

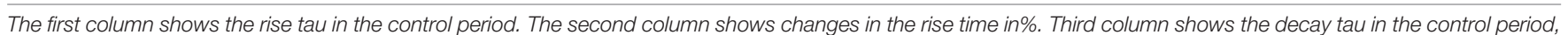
the fourth column shows changes in the decay time in\%. The fifth column shows the number of neurons ( $n$ ) and animals ( $N$ ) used for the experiments.

administration of secretin $(100 \mathrm{nM})$ resulted in a significant increase in the mean mPSC frequency reaching $147.6 \pm 19.19 \%$ of control values $(1.367 \pm 0.315 \mathrm{~Hz}, n=16$; Student's $t$-test; $p=0.0274$ ) (Figure 3A and Table 1). Elevation of the mPSC frequency started 1-3 min after administration of secretin. Cumulative probability plots also demonstrated significant differences between the control and the treated intereventintervals (Kolmogorov-Smirnov test, $p=0.0337$ ). Values of amplitude, rise $\tau$, and decay $\tau$ of the mPSCs presented no significant change (Figure 3A and Tables 2, 5).

Pretreatment of the slices with secretin receptor antagonist (secretin 5-27; $3 \mu \mathrm{M}) 15 \mathrm{~min}$ before the application of secretin $(100 \mathrm{nM})$, eliminated the stimulatory action of secretin on the mean frequency of mPSCs $(92.88 \pm 8.949 \%)$ (Figure 3B and Table 1). Cumulative probability plots also showed no significant differences between the control and the treated intereventintervals (Kolmogorov-Smirnov test, $p=0.999$ ). Values of mPSC amplitude, rise and decay $\tau$ presented no significant change (Figure 3B and Tables 2, 5).

In order to prove the direct action of secretin in GnRH neurons, its effect on the mPSCs was further examined in the intracellular presence of the G-protein blocker GDP- $\beta$-S $(2 \mathrm{mM})$. The blockade of G-proteins in $\mathrm{GnRH}$ neurons eliminated the observed effect of secretin on mPSCs $(102.1 \pm 0.957 \%)$ (Figure 3C and Table 1). Cumulative probability plots showed no significant differences between the control and the treated interevent-intervals (KolmogorovSmirnov test, $p=0.819$ ). Values of amplitude and shape of the PSCs also presented no significant changes (Figure 3C and Tables 2, 5). 

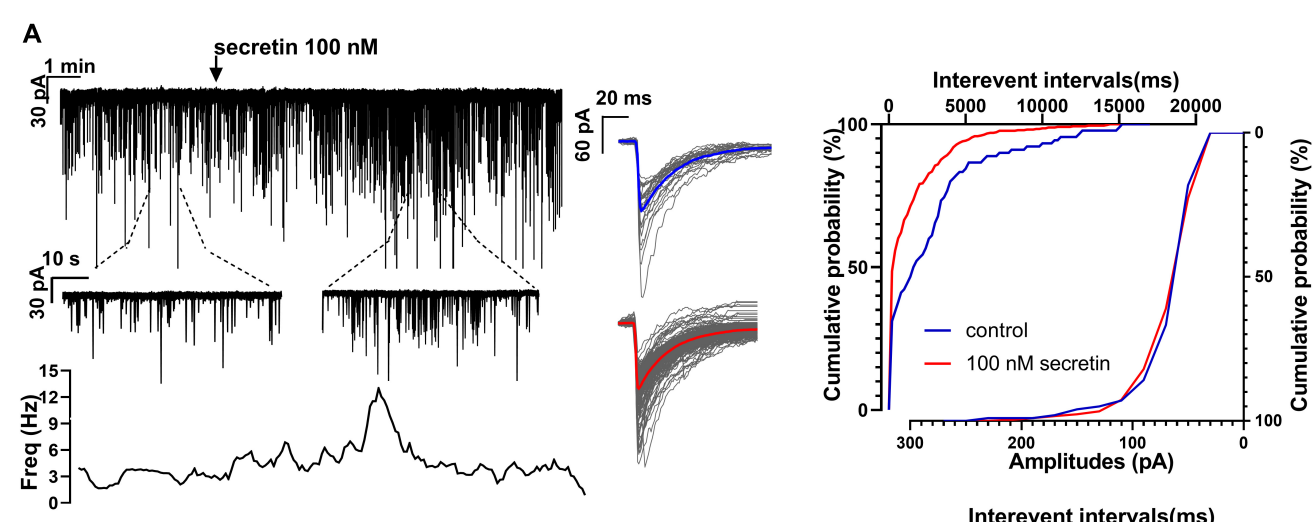

B secretin receptor antagonist+secretin $100 \mathrm{nM}$
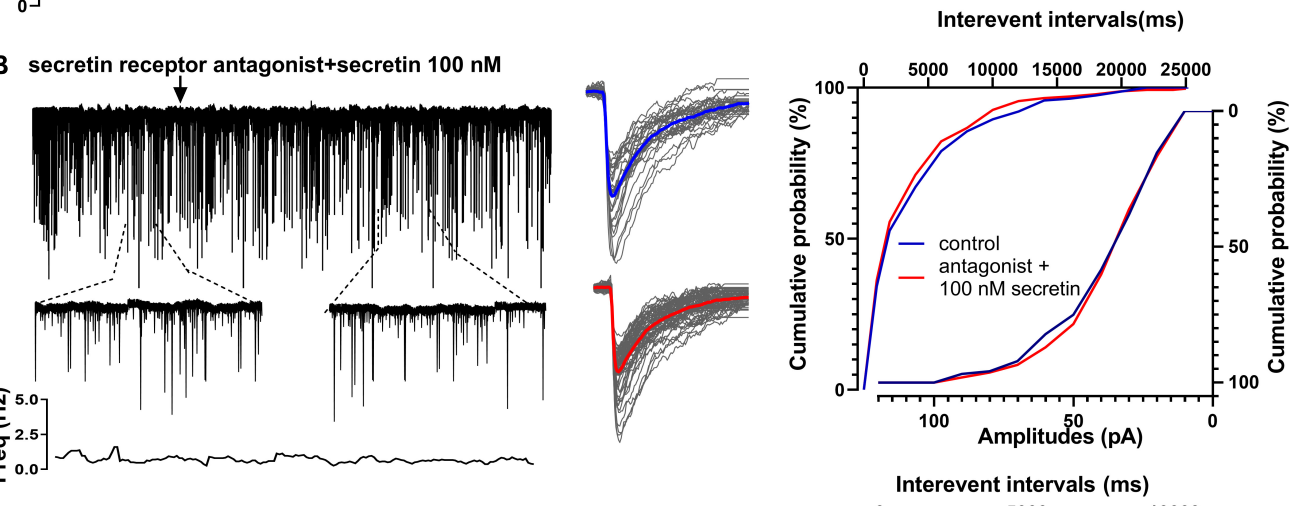

C GDP- $\beta-\mathrm{S}+$ secretin $100 \mathrm{nM}$
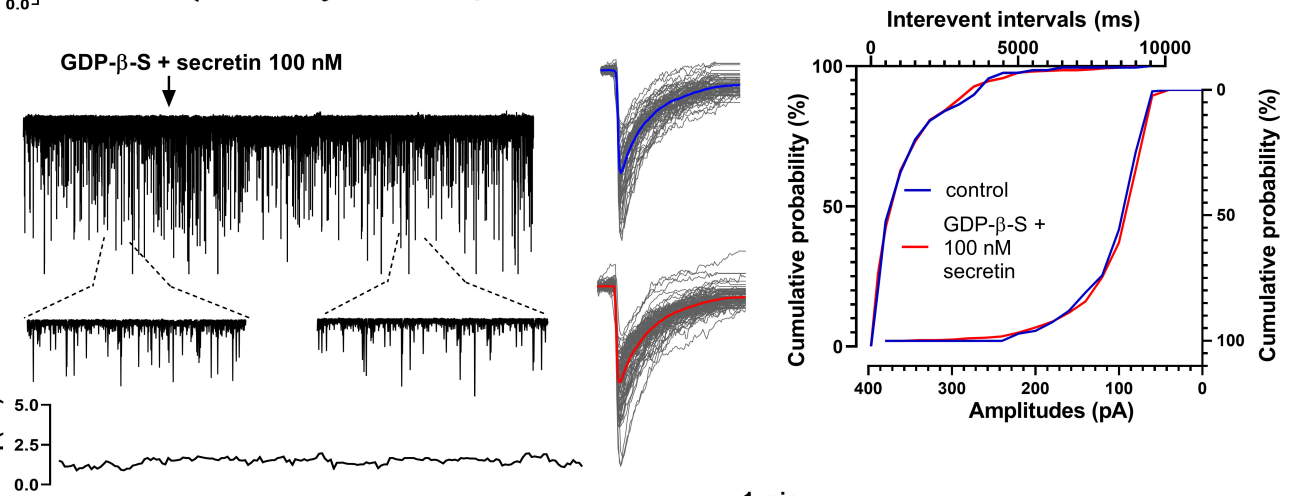

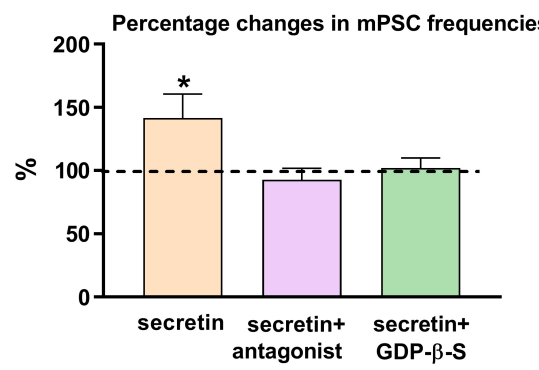

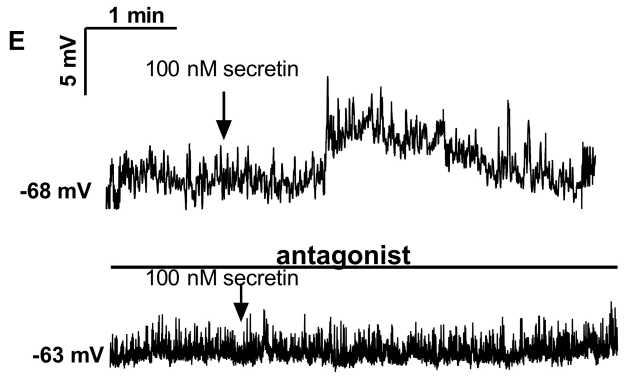

FIGURE 3 | Secretin elevates the frequency of mPSCs of GnRH neurons directly via secretin receptor. (A) Secretin (100 nM) increased the frequency of mPSCs in $\mathrm{GnRH}$ neurons, as shown in a representative recording, the 1 min zoomed periods, the frequency distribution and the cumulative probability of IEls graphs. There was no change in the average amplitude or in the shape of the events representing the individual PSCs beside the recording. (B) Pretreatment of the brain slice with secretin receptor antagonist (Secretin 5-27) eliminated the effect of secretin on GnRH neurons. (C) Intracellular application of G-protein blocker, GDP- $\beta$-S also abolished the effect of secretin. (D) Bar graph shows that the effect of secretin was mediated via the G-protein coupled secretin receptor. (E) Depolarization in the resting potential is demonstrated in a 4 min period. Arrow shows application of secretin. The bottom recording, in the presence of secretin receptor antagonist shows no significant change after the administration of secretin $(100 \mathrm{nM})\left({ }^{*} p<0.05\right)$. The inserts below the 15 min recordings are $1-1$ min zoomed periods from the recordings before and after secretin administration. The frequency distribution is also presented under each recording. Average mPSCs next to the recording represent no change in the shape of events after secretin treatment. Cumulative probabilities of the interevent intervals and amplitudes are graphed next to the individual events. Arrow shows the administration of secretin $\left({ }^{*} p<0.05\right)$. 
Bar graph summarizes the effect of secretin on the mean frequency of the mPSCs and full inhibition of the secretin-triggered action by antagonizing secretin receptor and the intracellular blockade of $\mathrm{G}$-proteins in $\mathrm{GnRH}$ neurons (Figure 3D and Table 1).

Current clamp measurements revealed that secretin (100 nM) triggered membrane depolarization in $\mathrm{GnRH}$ neurons in the presence of TTX. The mean of the changes was $12.74 \pm 4.539 \mathrm{mV}$ (Student's $t$-test, $n=6, p=0.0186$ ) (Figure 3E). Depolarization usually occurred $1 \mathrm{~min}$ after secretin application and as the figure shows it returned to the baseline after a short time. In the presence of secretin receptor antagonist, the observed stimulating effect did not occur, there was no significant change in the membrane potential $(n=5)$ (Figure 3E).

\section{Involvement of PKA and Retrograde NO Signaling Mechanisms in the Effect of Secretin}

Changes in the frequency of mPSCs but not in the amplitude suggested changes in the presynaptic site after application of secretin. Previous studies have demonstrated that activation of the retrograde NO signaling pathway in GnRH neurons results in an increased mPSC frequency (Farkas et al., 2016). To test the hypothesis that retrograde NO signaling mediates the effect of secretin on the GABAergic synaptic input of $\mathrm{GnRH}$ neurons NPLA (1 $\mu \mathrm{M})$, an nNOS blocker, was applied intracellularly into the recorded $\mathrm{GnRH}$ neurons $15 \mathrm{~min}$ before adding secretin (100 nM). Intracellular application of NPLA alone did not alter basal frequency or amplitude of mPSCs in GnRH neurons (Farkas et al., 2016; Figure 4A and Table 1). NPLA treatment fully eliminated the action of secretin $(90.38 \pm 4.60 \%$, Student's $t$-test, $p=0.0746)$. Cumulative probability plots showed no significant differences between the control and the treated intereventintervals (Kolmogorov-Smirnov test, $p=0.998$ ). Values of amplitude and rise and decay $\tau$ of the PSCs also presented no significant changes (Figure 4A and Tables 2, 5).

Nitric oxide activation can be induced via different intracellular signaling pathways. Earlier studies showed that one of the main pathways activated by secretin receptor is the cAMP/PKA pathway (Siu et al., 2006). Therefore, the selective PKA blocker KT5720 was applied intracellularly into GnRH neurons. The presence of KT5720 in the intracellular solution abolished the frequency increasing effect of secretin on mPSCs of GnRH neurons (97 $\pm 5.987 \%$ ) (Figure $4 \mathbf{B}$ and Table 1). Cumulative probability plots represented no significant differences between the control and the treated interevent intervals (Kolmogorov-Smirnov test, $p=0.491$ ). Values of amplitude, the rise and the decay $\tau$ of mPSCs also presented no significant changes (Figure $\mathbf{4 B}$ and Tables 2, 5). Bar graph depicts the full inhibition of the secretin-triggered action on mPSCs by intracellularly applied NPLA and KT5720 (Figure 4C and Table 1).

In summary, these results demonstrate that secretin acts directly on GnRH neurons via secretin receptors and activates the cAMP/PKA/nNOS pathway which enables the generation of $\mathrm{NO}$ in the recorded GnRH neurons in male mice. The retrograde messenger can reach the GABAergic synaptic boutons and increases the release of GABA enhancing frequency of GABAergic mPSCs of GnRH neurons as seen on the schematic illustration (Figure 5).

\section{DISCUSSION}

Secretin has been shown to modulate the HPG axis, however, the sites of action have not been explored so far (Kimura et al., 1987). The present study provides electrophysiological evidence for a direct action of secretin on $\mathrm{GnRH}$ neurons. Accordingly: (1) Secretin activated the secretin receptors directly in GnRH neurons and increased the frequency of their APs and GABAergic mPSCs. (2) Downstream signaling of secretin receptor involved the activation of PKA and nNOS that in turn, led to activation of the retrograde NO signaling pathway. The release of NO enhances the release of GABA from the presynaptic sites which has an excitatory effect on $\mathrm{GnRH}$ neurons via $\mathrm{GABA}_{\mathrm{A}}-\mathrm{R}$.

\section{Secretin Is Excitatory on GnRH Neurons via Secretin Receptor}

The present findings demonstrate that secretin exerts excitatory effects on GnRH neurons. Frequency of PSCs and APs increased, the rheobase of evoked APs decreased, and the membrane potential depolarized upon secretin administration. These data are parallel with other investigations showing the stimulatory effect of secretin in different brain areas and different cell types. In the PVN secretin elevated the firing rate in vivo, and in the nucleus of the solitary tract (NTS) it depolarized neurons via nonselective cationic channels (Yang et al., 2004; Chen et al., 2013). Both central and peripheral administration of secretin induced c-Fos expression in the PVN and the arcuate nucleus, suggesting the activation of these hypothalamic nuclei (Cheng et al., 2011).

Both the GABAergic mPSC frequency and the firing rate were increased in $\mathrm{GnRH}$ neurons after secretin administration. Since GABA has a special excitatory effect on GnRH neurons via $\mathrm{GABA}_{A}-\mathrm{R}$ (Sullivan et al., 2003; Farkas et al., 2010), the elevation detected in $\mathrm{mPSC}$ frequency and the increased firing rate correlate well.

Although the recorded mPSCs of GnRH neurons in male mice are GABAergic under basal conditions, we could not exclude the theoretical possibility of the additional effects of glutamate on these parameters (Sullivan and Moenter, 2003; Moenter and DeFazio, 2005; Yin et al., 2008; Farkas et al., 2010; Herbison and Moenter, 2011). The selective inhibition of $\mathrm{GABA}_{\mathrm{A}}$ receptors with picrotoxin, however, totally abolished the effect of secretin on PSCs, indicating the exclusive role of GABAergic inputs in the effects of secretin.

We proved that the effect of secretin is specific to secretin receptor using secretin receptor antagonist. In addition, the intracellular blockade of secretin receptor by the membrane impermeable G-protein blocker, GDP- $\beta$-S, also abolished the secretin-evoked changes in the mPSC frequency, proving that secretin action occurs postsynaptically on GnRH neurons.

A previous study has reported that secretin augmented plasma $\mathrm{LH}$ concentration following its stereotaxic delivery into mPOA 

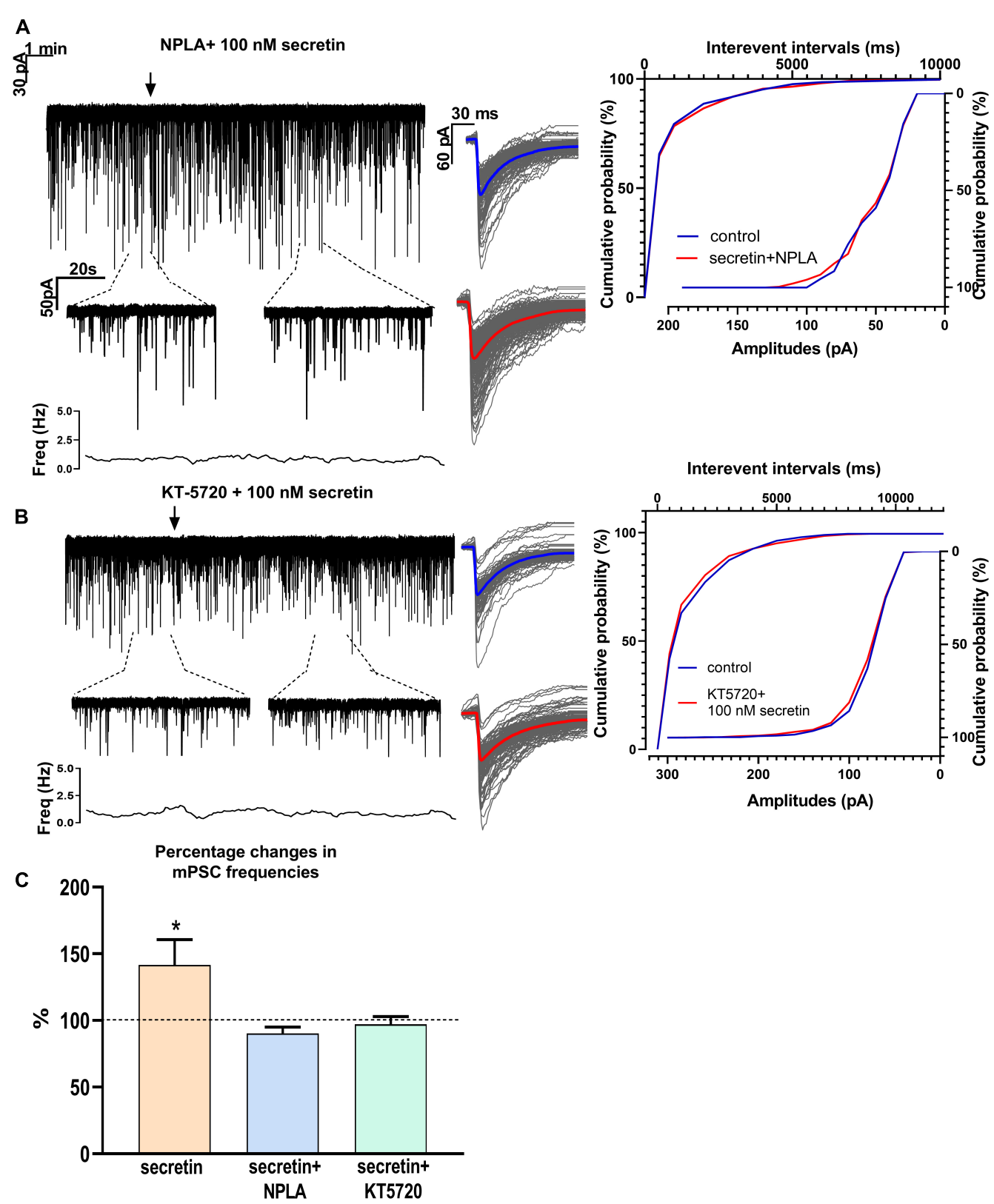

FIGURE 4 | Effects of various blockers on the secretin-evoked increase in the frequency of mPSCs in GnRH neurons. (A) Intracellular application of the nNOS blocker NPLA extinguished the effect of secretin. (B) The PKA inhibitor KT5720 applied intracellularly, also eliminated the effect of secretin. (C) Bar graph shows that secretin utilizes PKA- and retrograde NO-coupled signaling mechanisms. The inserts below the 15 min recordings are 1-1 min zoomed periods from the recordings before and after secretin administration. The frequency distribution is also presented under each recording Average mPSCs beside each recording showed change in the shape or amplitudes of events after secretin treatment. Cumulative probabilities of the interevent intervals are graphed next to the individual events. Arrow shows the administration of secretin $(* p<0.05)$.

suggesting that the effect of secretin on $\mathrm{LH}$ cells and $\mathrm{LH}$ production was indirect, and presumably the activation occurred at the level of GnRH neurons (Kimura et al., 1987). Our findings confirm that secretin is capable of centrally regulating the HPG axis via a direct activation of $\mathrm{GnRH}$ neurons.

Changes in the frequency of GABAergic mPSCs but not in their amplitude suggest that alterations take place at the presynaptic site. This might indicate that secretin has a direct effect at the presynaptic site via secretin receptors as it was discovered in an earlier work from the Purkinje cells of cerebellum (Yung et al., 2001). In our study, the intracellular blockade of the G-proteins and the NO pathway in the postsynaptic GnRH neurons eliminated the effect of secretin excluding this opportunity.

The hyperpolarizing current step measurements showed that input resistance (and therefore membrane resistance) has 


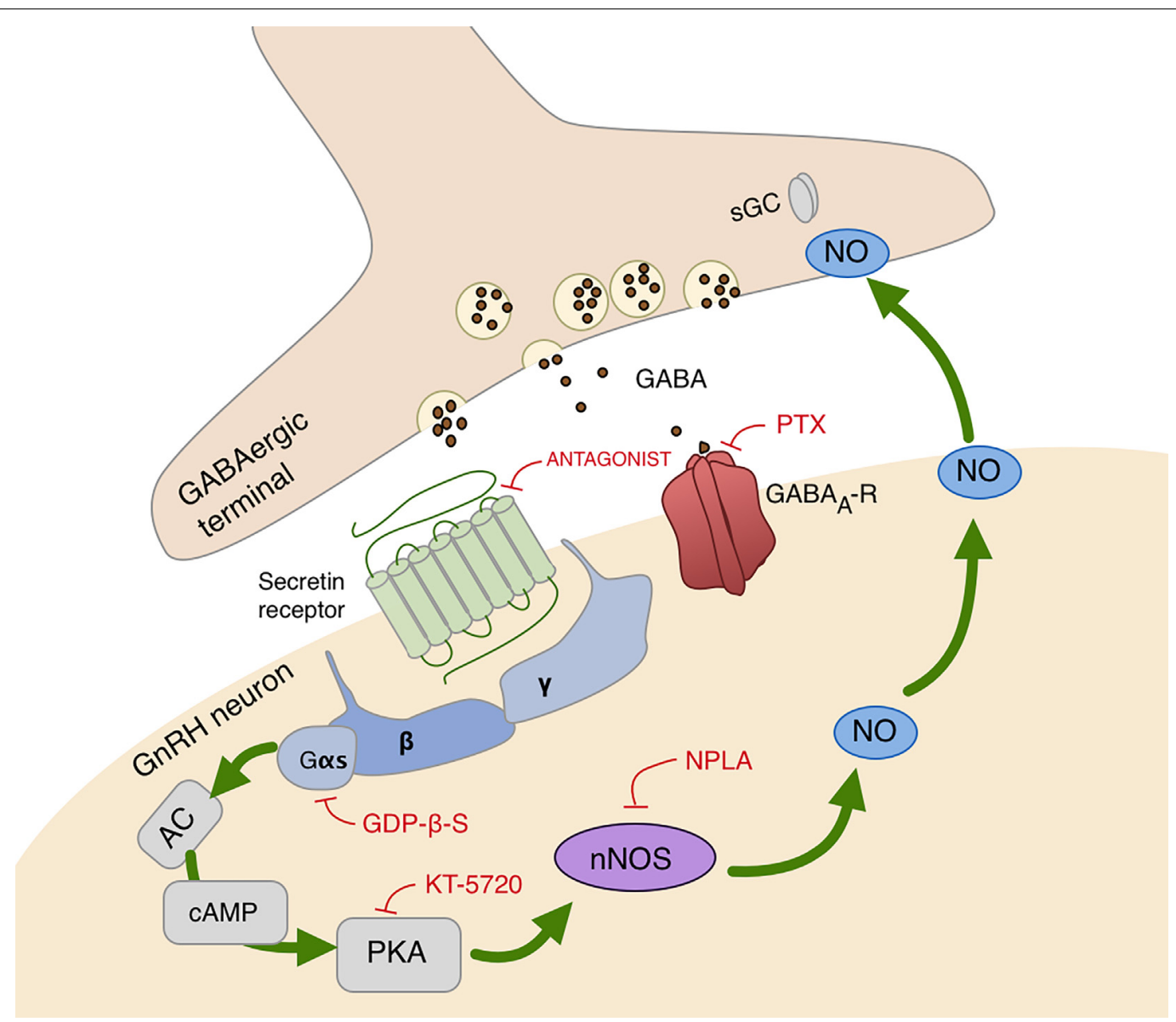

FIGURE 5 | Schematic illustration of secretin receptor signaling in GnRH neurons. Secretin activates cAMP/PKA/nNOS pathway and generates NO that binds to its presynaptic receptor, SGC, located in the GABAergic terminals. This signaling process increases the release of GABA, therefore, facilitates the synaptic inputs to

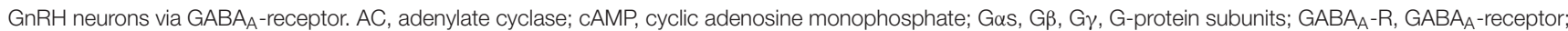
PTX, picrotoxin, selective GABA $A_{A}$-receptor blocker; PKA, protein kinase A; KT5720, protein kinase A inhibitor; nNOS, neuronal nitric oxide synthase; NPLA, nNOS inhibitor; GDP- $\beta-S$, G-protein inhibitor; sGC, soluble guanylyl cyclase, NO receptor. Red lines depict inhibitory actions, green arrows refer to the signal transduction pathway resulting in excitatory action of NO.

not changed upon secretin application and the subsequent GABA release. This seems to be in contrast with the data revealing a secretin-dependent depolarization of $V_{\text {rest }}$ when the current step is zero. One of the putative explanations for this observation is that response to GABA can be voltagedependent, provided presence of $G_{A B A}-R$ in the neuron (Shefner and Osmanovic, 1991). It is well known that $\mathrm{GnRH}$ neurons bear $\mathrm{GABA}_{\mathrm{B}}-\mathrm{R}$ (Herbison and Moenter, 2011; Liu and Herbison, 2011) suggesting a putative voltage-dependency of GABA response in GnRH neurons. This opportunity, however, requires further elaboration.

\section{Secretin Activates the Retrograde NO Signaling Pathway via cAMP/PKA Upregulation}

Our results indicate that secretin acts directly on $\mathrm{GnRH}$ neurons via secretin receptors whose activation triggers a downstream cascade event leading to activation of retrograde NO signaling in GnRH neurons. The mechanism of secretin's effect is often linked to NO production at the periphery (Konturek et al., 1997; Jyotheeswaran et al., 2000; Grossini et al., 2013). Within the brain, increase in the frequency of the GABAergic mPSCs could be evoked by activation of the NO machinery in hypothalamic neurons (Di et al., 2009). Previously, the presence and the activity of nNOS have been demonstrated by our group in GnRH neurons of mice. In these studies, the activation of nNOS increased the frequency of GABAergic mPSCs in GnRH neurons (Farkas et al., 2016, 2018). Stimulatory effect of retrograde NO signaling on GABAergic currents was described earlier in the PVN, where NO excited the GABAergic mPSCs in the neurons of PVN (Bains and Ferguson, 1997). NO also activated the GABAergic inputs of oxytocin- and vasopressin-containing neurons in the SON (Stern and Ludwig, 2001). The stimulatory effect of retrograde NO signaling was also proved in case of glutamatergic neural circuits, where NO released from the postsynaptic neurons could increase the probability of glutamate release from presynaptic glutamatergic axon terminals in different brain areas 
(O’Dell et al., 1991; Arancio et al., 1996; Micheva et al., 2003; Neitz et al., 2011).

All members of the B1 family of G-protein coupled receptors such as, VIP, secretin, and pituitary adenylate cyclase-activating peptide (PACAP) stimulate the adenylate cyclase via stimulatory G-protein (Gs) (Roth et al., 1984; Fremeau et al., 1986; Harmar, 2001) resulting in PKA activation (Siu et al., 2006) via Gs protein. The presence of PKA in GnRH secreting neurons was found earlier (Hoddah et al., 2009), and we also revealed that the application of PKA blocker totally inhibited the effect of secretin, providing further evidence that the underlying mechanism of secretin requires $\mathrm{PKA}$ activation.

The present findings demonstrate that secretin acted postsynaptically and resulted in a change of mPSC frequency, suggesting that secretin receptor activates the cAMP/PKA/nNOS pathway and generates NO that binds to its presynaptic receptor, soluble guanylyl cyclase (sGC), located in the GABAergic axon terminals. The expression of sGC has been recently detected in GABAergic and glutamatergic presynaptic boutons of $\mathrm{GnRH}$ neurons (Farkas et al., 2016, 2018). This retrograde signaling process increases the release of GABA, therefore, facilitates the synaptic inputs to $\mathrm{GnRH}$ neurons via $\mathrm{GABA}_{\mathrm{A}}$-receptor. PACAP and VIP can also activate nNOS and the production of NO via the cAMP/PKA/nNOS pathway in PC12 cells (Onoue et al., 2002).

These current results support further the concept that GnRH neurons can sense the metabolic state of the organism and strengthen the view that secretin may exert a central regulatory role on the HPG axis via acting upon hypophysiotropic GnRH neurons.

\section{REFERENCES}

Arancio, O., Kiebler, M., Lee, C. J., Lev-Ram, V., Tsien, R. Y., Kandel, E. R., et al. (1996). Nitric oxide acts directly in the presynaptic neuron to produce long-term potentiation in cultured hippocampal neurons. Cell 87, 1025-1035. doi: 10.1016/s0092-8674(00)81797-3

Bains, J. S., and Ferguson, A. V. (1997). Nitric oxide regulates NMDA-driven GABAergic inputs to type I neurones of the rat paraventricular nucleus. J. Physiol. 499(Pt 3), 733-746. doi: 10.1113/jphysiol.1997.sp021965

Banks, W. A., Goulet, M., Rusche, J. R., Niehoff, M. L., and Boismenu, R. (2002). Differential transport of a secretin analog across the blood-brain and blood-cerebrospinal fluid barriers of the mouse. J. Pharmacol. Exp. Ther. 302, 1062-1069. doi: 10.1124/jpet.102.036129

Barash, I. A., Cheung, C. C., Weigle, D. S., Ren, H., Kabigting, E. B., Kuijper, J. L., et al. (1996). Leptin is a metabolic signal to the reproductive system. Endocrinology 137, 3144-3147. doi: 10.1210/endo.137.7.8770941

Barbour, B. (2014). Electronics for Electrophysiologists. Available at: http://www. biologie.ens.fr/ barbour/electronics_for_electrophysiologists.pdf

Bayliss, W. M., and Starling, E. H. (1902). The mechanism of pancreatic secretion. J. Physiol. 28, 325-353.

Berthoud, H. R. (2008). Vagal and hormonal gut-brain communication: from satiation to satisfaction. Neurogastroenterol. Motil. 20(Suppl. 1), 64-72. doi: 10.1111/j.1365-2982.2008.01104.x

Cattanach, B. M., Iddon, C. A., Charlton, H. M., Chiappa, S. A., and Fink, G. (1977). Gonadotrophin-releasing hormone deficiency in a mutant mouse with hypogonadism. Nature 269, 338-340. doi: 10.1038/ $269338 \mathrm{a} 0$

Chen, X. Y., Wang, H., Xue, Y., and Chen, L. (2013). Modulation of paraventricular firing rate by secretin in vivo. Neurosci. Lett. 532, 29-32. doi: 10.1016/j.neulet. 2012.10.055

\section{DATA AVAILABILITY}

All datasets generated for this study are included in the manuscript/supplementary files.

\section{AUTHOR CONTRIBUTIONS}

VC wrote the manuscript and carried out electrophysiological measurements. CV and ZL designed the experiments and wrote the manuscript. IF designed the experiments, wrote the manuscript and carried out electrophysiological measurements.

\section{FUNDING}

This work was supported by the National Research, Development and Innovation Office (K115984 and K128278).

\section{ACKNOWLEDGMENTS}

The authors thank Dr. Suzanne M. Moenter (Department of Molecular and Integrative Physiology, University of Michigan, Ann Arbor, MI, United States) for kindly providing the GnRH-GFP transgenic mice. The authors wish to acknowledge Dr. Zoltán Péterfi (Department of Endocrine Neurobiology, Institute of Experimental Medicine, Hungarian Academy of Sciences, Hungary) for the thorough reading of the manuscript.

Cheng, C. Y., Chu, J. Y., and Chow, B. K. (2011). Central and peripheral administration of secretin inhibits food intake in mice through the activation of the melanocortin system. Neuropsychopharmacology 36, 459-471. doi: 10.1038/ npp. 2010.178

Chow, B. S., Chew, E. G., Zhao, C., Bathgate, R. A., Hewitson, T. D., and Samuel, C. S. (2012). Relaxin signals through a RXFP1-pERK-nNOS-NO-cGMPdependent pathway to up-regulate matrix metalloproteinases: the additional involvement of iNOS. PLoS One 7:e42714. doi: 10.1371/journal.pone.0042714

Chu, J. Y., Lee, L. T., Lai, C. H., Vaudry, H., Chan, Y. S., Yung, W. H., et al. (2009). Secretin as a neurohypophysial factor regulating body water homeostasis. Proc. Natl. Acad. Sci. U.S.A. 106, 15961-15966. doi: 10.1073/pnas.0903695106

Chu, J. Y., Yung, W. H., and Chow, B. K. (2006). Endogenous release of secretin from the hypothalamus. Ann. N. Y. Acad. Sci. 1070, 196-200. doi: 10.1196/ annals.1317.012

Di, S., Maxson, M. M., Franco, A., and Tasker, J. G. (2009). Glucocorticoids regulate glutamate and GABA synapse-specific retrograde transmission via divergent nongenomic signaling pathways. J. Neurosci. 29, 393-401. doi: 10. 1523/jneurosci.4546-08.2009

Dogrukol-Ak, D., Tore, F., and Tuncel, N. (2004). Passage of VIP/PACAP/secretin family across the blood-brain barrier: therapeutic effects. Curr. Pharm. Des. 10, 1325-1340. doi: 10.2174/1381612043384934

Farkas, I., Balint, F., Farkas, E., Vastagh, C., Fekete, C., and Liposits, Z. (2018). Estradiol increases glutamate and GABA neurotransmission into GnRH neurons via retrograde NO-signaling in proestrous mice during the positive estradiol feedback period. eNeuro 5, 1-19. doi: 10.1523/eneuro.005718.2018

Farkas, I., Kallo, I., Deli, L., Vida, B., Hrabovszky, E., Fekete, C., et al. (2010). Retrograde endocannabinoid signaling reduces GABAergic synaptic transmission to gonadotropin-releasing hormone neurons. Endocrinology 151, 5818-5829. doi: 10.1210/en.2010-0638 
Farkas, I., Vastagh, C., Farkas, E., Balint, F., Skrapits, K., Hrabovszky, E., et al. (2016). Glucagon-like peptide-1 excites firing and increases GABAergic miniature postsynaptic currents (mPSCs) in gonadotropin-releasing hormone $(\mathrm{GnRH})$ neurons of the male mice via activation of nitric oxide (NO) and suppression of endocannabinoid signaling pathways. Front. Cell Neurosci. 10:214. doi: 10.3389/fncel.2016.00214

Farkas, I., Vastagh, C., Sarvari, M., and Liposits, Z. (2013). Ghrelin decreases firing activity of gonadotropin-releasing hormone $(\mathrm{GnRH})$ neurons in an estrous cycle and endocannabinoid signaling dependent manner. PLoS One 8:e78178. doi: 10.1371 /journal.pone.0078178

Filpa, V., Carpanese, E., Marchet, S., Prandoni, V., Moro, E., Lecchini, S., et al. (2015). Interaction between NMDA glutamatergic and nitrergic enteric pathways during in vitro ischemia and reperfusion. Eur. J. Pharmacol. 750, 123-131. doi: 10.1016/j.ejphar.2015.01.021

Fremeau, R. T. Jr., Jensen, R. T., Charlton, C. G., Miller, R. L., O’Donohue, T. L., Moody, T. W., et al. (1983). Secretin: specific binding to rat brain membranes. J. Neurosci. 3, 1620-1625. doi: 10.1523/jneurosci.03-08-01620.1983

Fremeau, R. T. Jr., Korman, L. Y., and Moody, T. W. (1986). Secretin stimulates cyclic AMP formation in the rat brain. J. Neurochem. 46, 1947-1955. doi: 10.1111/j.1471-4159.1986.tb08518.x

Giacobini, P., and Wray, S. (2007). Cholecystokinin directly inhibits neuronal activity of primary gonadotropin-releasing hormone cells through cholecystokinin-1 receptor. Endocrinology 148, 63-71. doi: 10.1210/en.2006-0758

Glovaci, I., Caruana, D. A., and Chapman, C. A. (2014). Dopaminergic enhancement of excitatory synaptic transmission in layer II entorhinal neurons is dependent on D(1)-like receptor-mediated signaling. Neuroscience 258, 7483. doi: 10.1016/j.neuroscience.2013.10.076

Gong, L., Gao, F., Li, J., Li, J., Yu, X., Ma, X., et al. (2015). Oxytocin-induced membrane hyperpolarization in pain-sensitive dorsal root ganglia neurons mediated by $\mathrm{Ca}(2+) / \mathrm{nNOS} / \mathrm{NO} / \mathrm{KATP}$ pathway. Neuroscience $289,417-428$. doi: 10.1016/j.neuroscience.2014.12.058

Grossini, E., Molinari, C., Morsanuto, V., Mary, D. A., and Vacca, G. (2013). Intracoronary secretin increases cardiac perfusion and function in anaesthetized pigs through pathways involving beta-adrenoceptors and nitric oxide. Exp. Physiol. 98, 973-987. doi: 10.1113/expphysiol.2012.070607

Harmar, A. J. (2001). Family-B G-protein-coupled receptors. Genome Biol. 2, Reviews3013.1- Reviews3013.10.

Herbison, A. E. (2016). Control of puberty onset and fertility by gonadotropinreleasing hormone neurons. Nat. Rev. Endocrinol. 12, 452-466. doi: 10.1038/ nrendo. 2016.70

Herbison, A. E., and Moenter, S. M. (2011). Depolarising and hyperpolarising actions of $\mathrm{GABA}(\mathrm{A})$ receptor activation on gonadotrophin-releasing hormone neurones: towards an emerging consensus. J. Neuroendocrinol. 23, 557-569. doi: $10.1111 / \mathrm{j} .1365-2826.2011 .02145 . \mathrm{x}$

Hill, J. W., and Elias, C. F. (2018). Neuroanatomical framework of the metabolic control of reproduction. Physiol. Rev. 98, 2349-2380. doi: 10.1152/physrev. 00033.2017

Hoddah, H., Marcantoni, A., Comunanza, V., Carabelli, V., and Carbone, E. (2009). L-type channel inhibition by $\mathrm{CB} 1$ cannabinoid receptors is mediated by PTXsensitive G proteins and cAMP/PKA in GT1-7 hypothalamic neurons. Cell Calcium 46, 303-312. doi: 10.1016/j.ceca.2009.08.007

Jyotheeswaran, S., Li, P., Chang, T. M., and Chey, W. Y. (2000). Endogenous nitric oxide mediates pancreatic exocrine secretion stimulated by secretin and cholecystokinin in rats. Pancreas 20, 401-407. doi: 10.1097/00006676200005000-00011

Kaneko, T., Kaneda, K., Ohno, A., Takahashi, D., Hara, T., Amano, T., et al. (2016). Activation of adenylate cyclase-cyclic AMP-protein kinase A signaling by corticotropin-releasing factor within the dorsolateral bed nucleus of the stria terminalis is involved in pain-induced aversion. Eur. J. Neurosci. 44, 2914-2924. doi: 10.1111/ejn.13419

Keshavarzi, S., Power, J. M., Albers, E. H., Sullivan, R. K., and Sah, P. (2015). Dendritic Organization of olfactory inputs to medial amygdala neurons. J. Neurosci. 35, 13020-13028. doi: 10.1523/jneurosci.0627-15.2015

Kimura, F., Mitsugi, N., Arita, J., Akema, T., and Yoshida, K. (1987). Effects of preoptic injections of gastrin, cholecystokinin, secretin, vasoactive intestinal peptide and PHI on the secretion of luteinizing hormone and prolactin in ovariectomized estrogen-primed rats. Brain Res. 410, 315-322. doi: 10.1016/ 0006-8993(87)90330-1

Klenke, U., Taylor-Burds, C., and Wray, S. (2014). Metabolic influences on reproduction: adiponectin attenuates $\mathrm{GnRH}$ neuronal activity in female mice. Endocrinology 155, 1851-1863. doi: 10.1210/en.2013-1677

Konturek, J. W., Hengst, K., Kulesza, E., Gabryelewicz, A., Konturek, S. J., and Domschke, W. (1997). Role of endogenous nitric oxide in the control of exocrine and endocrine pancreatic secretion in humans. Gut 40, 86-91. doi: 10.1136/gut.40.1.86

Koves, K., Kausz, M., Reser, D., and Horvath, K. (2002). What may be the anatomical basis that secretin can improve the mental functions in autism? Regul. Pept. 109, 167-172. doi: 10.1016/s0167-0115(02)00200-8

Liu, X., and Herbison, A. E. (2011). Estrous cycle- and sex-dependent changes in pre- and postsynaptic GABAB control of $\mathrm{GnRH}$ neuron excitability. Endocrinology 152, 4856-4864. doi: 10.1210/en.2011-1369

Matafome, P., Eickhoff, H., Letra, L., and Seica, R. (2017). Neuroendocrinology of adipose tissue and gut-brain axis. Adv. Neurobiol. 19, 49-70. doi: 10.1007/9783-319-63260-5_3

McDermott, C. M., and Schrader, L. A. (2011). Activation of kappa opioid receptors increases intrinsic excitability of dentate gyrus granule cells. J. Physiol. 589(Pt 14), 3517-3532. doi: 10.1113/jphysiol.2011.211623

Meis, S., Munsch, T., and Pape, H. C. (2002). Antioscillatory effects of nociceptin/orphanin FQ in synaptic networks of the rat thalamus. J. Neurosci. 22, 718-727. doi: 10.1523/jneurosci.22-03-00718.2002

Micheva, K. D., Buchanan, J., Holz, R. W., and Smith, S. J. (2003). Retrograde regulation of synaptic vesicle endocytosis and recycling. Nat. Neurosci. 6, 925-932. doi: 10.1038/nn1114

Moenter, S. M., and DeFazio, R. A. (2005). Endogenous gamma-aminobutyric acid can excite gonadotropin-releasing hormone neurons. Endocrinology 146, 5374-5379. doi: 10.1210/en.2005-2788

Neitz, A., Mergia, E., Eysel, U. T., Koesling, D., and Mittmann, T. (2011). Presynaptic nitric oxide/cGMP facilitates glutamate release via hyperpolarization-activated cyclic nucleotide-gated channels in the hippocampus. Eur. J. Neurosci. 33, 1611-1621. doi: 10.1111/j.1460-9568.2011. 07654.x

Nozaki, S., Nakata, R., Mizuma, H., Nishimura, N., Watanabe, Y., Kohashi, R., et al. (2002). In vitro autoradiographic localization of (125)i-secretin receptor binding sites in rat brain. Biochem. Biophys. Res. Commun. 292, 133-137. doi: 10.1006/bbrc.2002.6640

O’Dell, T. J., Hawkins, R. D., Kandel, E. R., and Arancio, O. (1991). Tests of the roles of two diffusible substances in long-term potentiation: evidence for nitric oxide as a possible early retrograde messenger. Proc. Natl. Acad. Sci. U.S.A. 88, 11285-11289. doi: 10.1073/pnas.88.24.11285

Onoue, S., Endo, K., Yajima, T., and Kashimoto, K. (2002). Pituitary adenylate cyclase activating polypeptide regulates the basal production of nitric oxide in PC12 cells. Life Sci. 71, 205-214. doi: 10.1016/s0024-3205(02)01639-9

Ponzio, T. A., and Hatton, G. I. (2005). Adenosine postsynaptically modulates supraoptic neuronal excitability. J. Neurophysiol. 93, 535-547. doi: 10.1152/jn. 01185.2003

Roa, J. (2013). Role of GnRH neurons and their neuronal afferents as key integrators between food intake regulatory signals and the control of reproduction. Int. J. Endocrinol. 2013:518046. doi: 10.1155/2013/518046

Roth, B. L., Beinfeld, M. C., and Howlett, A. C. (1984). Secretin receptors on neuroblastoma cell membranes: characterization of 125I-labeled secretin binding and association with adenylate cyclase. J. Neurochem. 42, 1145-1152. doi: 10.1111/j.1471-4159.1984.tb12723.x

Seidl, A. H., Rubel, E. W., and Barria, A. (2014). Differential conduction velocity regulation in ipsilateral and contralateral collaterals innervating brainstem coincidence detector neurons. J. Neurosci. 34, 4914-4919. doi: 10.1523/ jneurosci.5460-13.2014

Shefner, S. A., and Osmanovic, S. S. (1991). GABAA and GABAB receptors and the ionic mechanisms mediating their effects on locus coeruleus neurons. Prog. Brain Res. 88, 187-195. doi: 10.1016/S0079-6123(08)63808-X

Siu, F. K., Lam, I. P., Chu, J. Y., and Chow, B. K. (2006). Signaling mechanisms of secretin receptor. Regul. Pept. 137, 95-104. doi: 10.1016/j.regpep.2006.02.011

Spergel, D. J., Kruth, U., Hanley, D. F., Sprengel, R., and Seeburg, P. H. (1999). GABA- and glutamate-activated channels in green fluorescent protein-tagged 
gonadotropin-releasing hormone neurons in transgenic mice. J. Neurosci. 19, 2037-2050. doi: 10.1523/jneurosci.19-06-02037.1999

Stern, J. E., and Ludwig, M. (2001). NO inhibits supraoptic oxytocin and vasopressin neurons via activation of GABAergic synaptic inputs. Am. J. Physiol. Regul. Integr. Comp. Physiol. 280, R1815-R1822. doi: 10.1152/ajpregu. 2001.280.6.R1815

Sullivan, S. D., DeFazio, R. A., and Moenter, S. M. (2003). Metabolic regulation of fertility through presynaptic and postsynaptic signaling to gonadotropinreleasing hormone neurons. J. Neurosci. 23, 8578-8585. doi: 10.1523/jneurosci. 23-24-08578.2003

Sullivan, S. D., and Moenter, S. M. (2003). Neurosteroids alter gammaaminobutyric acid postsynaptic currents in gonadotropin-releasing hormone neurons: a possible mechanism for direct steroidal control. Endocrinology 144, 4366-4375. doi: 10.1210/en.2003-2634

Sullivan, S. D., and Moenter, S. M. (2004). Gamma-aminobutyric acid neurons integrate and rapidly transmit permissive and inhibitory metabolic cues to gonadotropin-releasing hormone neurons. Endocrinology 145, 1194-1202. doi: 10.1210/en.2003-1374

Suter, K. J., Song, W. J., Sampson, T. L., Wuarin, J. P., Saunders, J. T., Dudek, F. E., et al. (2000). Genetic targeting of green fluorescent protein to gonadotropinreleasing hormone neurons: characterization of whole-cell electrophysiological properties and morphology. Endocrinology 141, 412-419. doi: 10.1210/endo. 141.1.7279

Thiriet, M. (2019). Vasculopathies: Behavioral, Chemical, Environmental, and Genetic Factors. Basel: Springer International Publishing AG.

Toth, Z. E., Heinzlmann, A., Hashimoto, H., and Koves, K. (2013). Distribution of secretin receptors in the rat central nervous system: an in situ hybridization study. J. Mol. Neurosci. 50, 172-178. doi: 10.1007/s12031-012-9895-1

Ulrich, C. D. II, Holtmann, M., and Miller, L. J. (1998). Secretin and vasoactive intestinal peptide receptors: members of a unique family of $\mathrm{G}$ protein-coupled receptors. Gastroenterology 114, 382-397. doi: 10.1016/s0016-5085(98)70491-3

Ulrich-Lai, Y. M., Fulton, S., Wilson, M., Petrovich, G., and Rinaman, L. (2015). Stress exposure, food intake and emotional state. Stress 18, 381-399. doi: 10 3109/10253890.2015.1062981

Wang, R., Chow, B. K. C., and Zhang, L. (2018). Distribution and functional implication of secretin in multiple brain regions. J. Mol. Neurosci. 68, 485-493. doi: $10.1007 / \mathrm{s} 12031-018-1089-\mathrm{z}$
Welch, M. G., Keune, J. D., Welch-Horan, T. B., Anwar, N., Anwar, M., and Ruggiero, D. A. (2003). Secretin activates visceral brain regions in the rat including areas abnormal in autism. Cell. Mol. Neurobiol. 23, 817-837.

Wen, J. P., Lv, W. S., Yang, J., Nie, A. F., Cheng, X. B., Yang, Y., et al. (2008). Globular adiponectin inhibits GnRH secretion from GT1-7 hypothalamic GnRH neurons by induction of hyperpolarization of membrane potential. Biochem. Biophys. Res. Commun. 371, 756-761. doi: 10.1016/j.bbrc.2008. 04.146

Williams, M. R., Fuchs, J. R., Green, J. T., and Morielli, A. D. (2012). Cellular mechanisms and behavioral consequences of Kv1.2 regulation in the rat cerebellum. J. Neurosci. 32, 9228-9237. doi: 10.1523/jneurosci.6504-11. 2012

Yamashita, H., Inenaga, K., Okuya, S., Hattori, Y., and Yamamoto, S. (1989). Effect of brain-gut peptides upon neurons in centrally regulating sites for drinking. Arch. Histol. Cytol. 52(Suppl.), 121-127. doi: 10.1679/aohc.52.suppl_121

Yang, B., Goulet, M., Boismenu, R., and Ferguson, A. V. (2004). Secretin depolarizes nucleus tractus solitarius neurons through activation of a nonselective cationic conductance. Am. J. Physiol. Regul. Integr. Comp. Physiol. 286, R927-R934. doi: 10.1152/ajpregu.00600.2003

Yin, C., Ishii, H., Tanaka, N., Sakuma, Y., and Kato, M. (2008). Activation of A-type gamma-amino butyric acid receptors excites gonadotrophin-releasing hormone neurones isolated from adult rats. J. Neuroendocrinol. 20, 566-575. doi: 10.1111/j.1365-2826.2008.01697.x

Yung, W. H., Leung, P. S., Ng, S. S., Zhang, J., Chan, S. C., and Chow, B. K. (2001). Secretin facilitates GABA transmission in the cerebellum. J. Neurosci. 21, 7063-7068. doi: 10.1523/jneurosci.21-18-07063.2001

Conflict of Interest Statement: The authors declare that the research was conducted in the absence of any commercial or financial relationships that could be construed as a potential conflict of interest.

Copyright (c) 2019 Csillag, Vastagh, Liposits and Farkas. This is an open-access article distributed under the terms of the Creative Commons Attribution License (CC BY). The use, distribution or reproduction in other forums is permitted, provided the original author(s) and the copyright owner(s) are credited and that the original publication in this journal is cited, in accordance with accepted academic practice. No use, distribution or reproduction is permitted which does not comply with these terms. 